\title{
Unlocking the potential of SynBio for improving livelihoods in Africa
}

${ }^{a}$ Reagan Mudziwapasi, ${ }^{\mathrm{g} J o n a t h a n ~ M u f a n d a e d z a, ~}{ }^{\mathrm{b}}$ Fortune Ntengwa Jomane, ${ }^{\mathrm{d}}$ Fanuel Songwe, ${ }^{a}$ Abigarl Ndudzo, ${ }^{a}$ Rutendo Patricia Nyamusamba, ${ }^{\mathrm{g}}$ Annah R. Takombwa, ${ }^{\mathrm{a}}$ Melinda Gugulethu Mahla, ${ }^{\mathrm{a} J e s s i c a}$ Pullen, ${ }^{\mathrm{e}}$ Sibonani Sandra Mlambo, ${ }^{\mathrm{g}}$ Cyprian Mahuni, ${ }^{\mathrm{c}}$ Edward Mufandaedza, ${ }^{\mathrm{f}}$ Ryman Shoko

${ }^{\mathrm{a}}$ Department of Crop and Soil Sciences, Faculty of Agricultural Sciences, Lupane State University, P. O. Box 170, Lupane, Zimbabwe

${ }^{b}$ Department of Animal Science and Rangeland Management, Faculty of Agricultural Sciences, Lupane State University, P. O. Box 170, Lupane, Zimbabwe

${ }^{c}$ Department of Environmental Sciences, Faculty of Agricultural Sciences, Lupane State University, P. O. Box 170, Lupane, Zimbabwe

${ }^{\mathrm{d}}$ Department of Biosciences and Biotechnology, Faculty of Science and Technology, Midlands State University, P. O. Bag 9055, Gweru, Zimbabwe

${ }^{\mathrm{e}}$ Department of Biotechnology, Faculty of Agriculture, Chinhoyi University of Technology, P. O. Box 7724, Chinhoyi, Zimbabwe

${ }^{\mathrm{f}}$ Department of Biology, Faculty of Agriculture, Chinhoyi University of Technology, P. O. Box 7724, Chinhoyi, Zimbabwe

${ }^{\mathrm{g}}$ National Biotechnology Authority, 21 Princess Drive, Newlands, Harare, Zimbabwe

Corresponding author: shoko.ryman@gmail.com

\begin{abstract}
Synthetic biology (SynBio) is an interdisciplinary field that has developed rapidly in the last two decades. It involves the design and construction of new biological systems and processes from standardized biological components, networks and synthetic pathways. The goal of Synbio is to create logical forms of cellular control. Biological systems and their parts can be re-designed to carry out completely new functions. SynBio is poised to greatly impact human health, environment, biofuels and chemical production with huge economic benefits. SynBio presents opportunities for the highly agro-based African economies to overcome setbacks that threaten food security: The setbacks are brought about by climate change, land degradation, over-reliance on food imports, global competition, and water and energy security issues
\end{abstract}


among others. With appropriate regulatory frameworks and systems in place, the benefits of harnessing SynBio to boost development in African economies by far potentially outweigh the risks. Countries that are already using GMOs such as South Africa and Kenya should find the application of SynBio seamless, as it would be a matter of expanding the already existing regulations and policies for GMO use.

Key words: synthetic biology, food security, biosafety, regulation, GMO

\section{Introduction}

The past two decades have been characterised by a boom in a new interdisciplinary field anchored on the application of engineering principles in biology called synthetic biology (SynBio). It integrates scientific disciplines such as molecular biology, chemistry, (bio-) physics, computer-aided modelling and design (Millar-Haskell et al., 2019; König et al., 2013). The field involves the designing and constructing of entirely new biological systems (that may not be found in nature) and processes from standardized biological components, networks and synthetic pathways with the goal of creating logical forms of cellular control (Goñi-Moreno and Nikel, 2019; Pretorius, 2016; Jing Liang et al., 2011). It can be used to engineer and redesign biological systems so that they can be used in real-world applications. These can be in biosensing, biomanufacturing and biotherapy. They follow a typical designbuild-test cycle (Xiang et al., 2018). Inspired by computer science and electronics, synthetic gene circuits have been designed to control the flow of information in biological systems. SynBio offers the ability to redesign existing biological systems or their parts to carry out new functions (Enyeart et al., 2013; Lu et al., 2009; Chen et al., 2017). It makes use of interchangeable and standardized "biological-parts" so as to construct complex genetic networks that allow robust and tunable transgene expression in response to changes in signal input (Young and Alper, 2010; Guiziou et al., 2018). Using the same engineering principles, existing organisms can be redesigned for new or enhanced purposes to satisfy human needs. The key for development of biocomputing SynBio based approaches is in Boolean logic functions design and implementation in cells (normally encoded into genetic material). Logic gates, counters, multiplexers, adders, and memories have been engineered in cells. Through modifying cell-cell communication programmes, distributed computations have been designed and built in multicellular systems. Biological systems can solve relatively simple mathematical problems and compute intricate Boolean logic operations. They are a powerful 
platform for tackling bioproduction, diagnosis and bioremediation that were restricted to silicon-based computer technologies (Goñi-Moreno and Nikel, 2019). The last few years have witnessed a surge in the availability of tools and components that enable researchers to generate biological modules and genetic devices through modelling and rationalizing via engineering-driven approaches (Amos and Goñi-Moreno, 2018).

There is tangible evidence demonstrating that SynBio is poised to have major impacts in a number of fields such as human health, environment, biofuels and chemical production (Mcdaniel and Weiss, 2005; Serrano, 2007; Khalil and Collins, 2010; Schmidt, 2010). Engineering principles are now being applied to complex multigene constructs that include pathways and whole genomes. Where genes that are essential for a minimal bacterial genome are synthesised and at times transplanted into microbial cells. This has made feasible and simple previously impossible tasks (Goold et al., 2018). SynBio offers technologies such as whole cell biosensors that can be used in environmental monitoring, bioremediation, landmine detection as well as production of safer alternatives such as biodegradable plastics (Lee et al., 2006; Gogerty and Bobik, 2010; Teo, 2014, Belkin et al., 2017; Goold et al., 2018). SynBio is being propelled into prominence by the ever-decreasing costs of DNA sequencing and DNA synthesis and the increasing speed at which they are being accomplished. This is facilitating a paradigm shift in molecular sciences (Goold et al., 2018).

Of particular interest, in this paper, is the applicability of SynBio in agriculture extending beyond crop development. The far-reaching applications stretch from farm management to agri-intelligence systems right up to post-harvest stages to reduce risks of product spoilage (Liu and Jr, 2015). SynBio poses a huge economic potential with the global market expected to be valued at US\$38,7 billion by 2020 (Allied market research, 2019). Agriculture, which is one of the bedrock of African economies, faces an increasingly challenging future due to a lot of factors among them climate change, land degradation, over reliance on food imports, global competition, water and energy security issues (Conceição et al., 2016). With the continent's population continuing to increase, demand for food will also increase. Hence, food security becomes a paramount economic issue. Africa's present food production approaches are not capable of providing sufficient food without posing serious adverse environmental impact (Funk et al., 2008). 
SynBio can be an investable utility technology capable of ensuring that Africa meets and sustains its food security needs. However, while SynBio applications from areas other than agriculture have been predicted to offer great benefits by making products, they have also given rise to concerns about new safety, ethics and socio-economic risks (Dana et al., 2012; Edwards, 2014; Ribeiro and Shapira, 2018). Whilst SynBio may present benefits for the economy at large, its use in the production of compounds commonly extracted from natural plants could have negative effects on communities which grow/harvest those plants. Common examples include replacement of the anti-malarial artemisinin produced from the plant Artemisia annua with artemisin produced using SynBio and the production of flavors using SynBio as opposed to conventional agriculture (Path, 2013; Mitchell, 2018). This could deprive African farmers of income due to reduced demands for their products (Oldham et al., 2012; Goold et al., 2018).

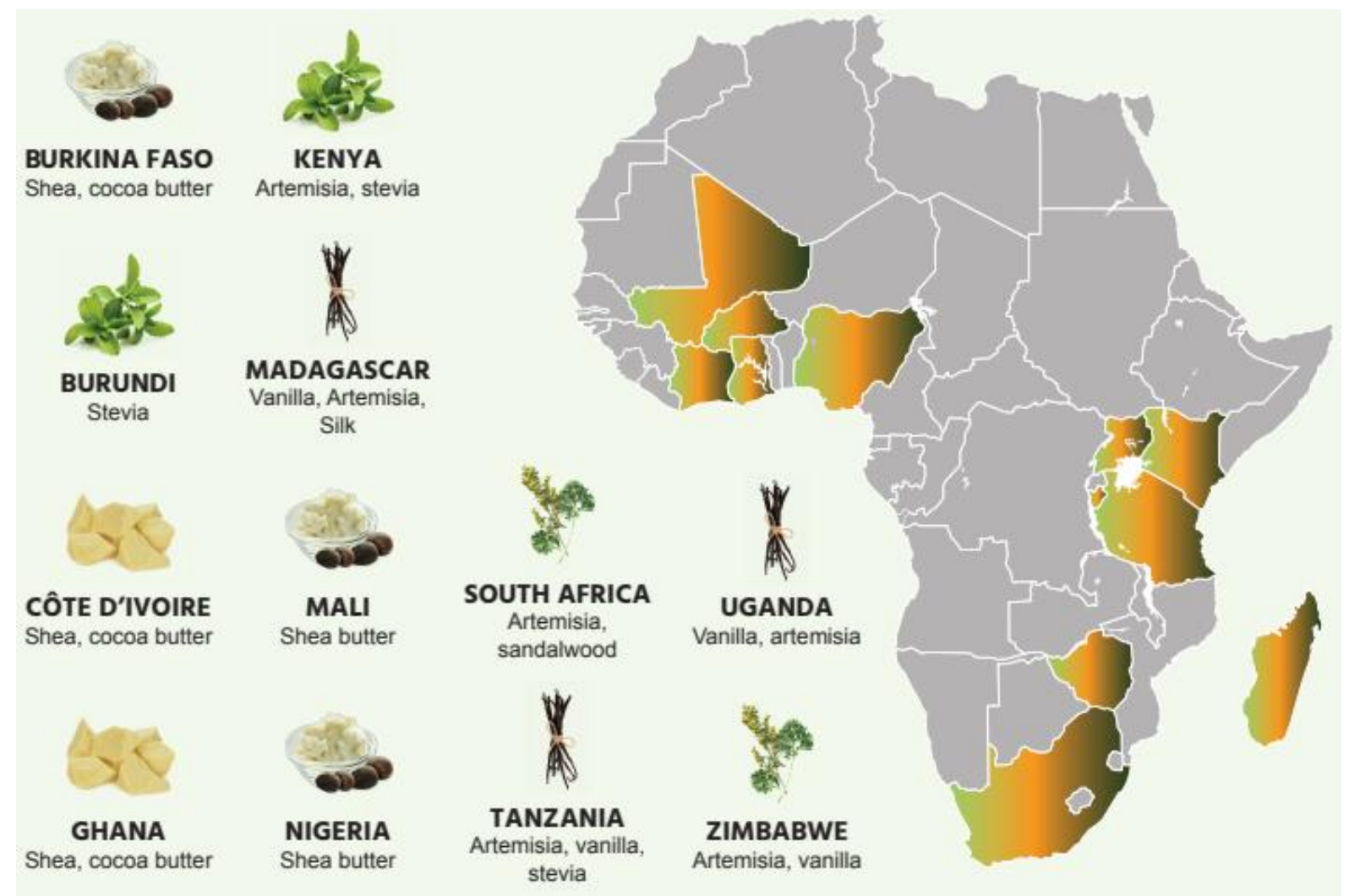

(Adapted from ETC Group et al., 2018)

Figure 1: The map illustrates where some natural crops are produced in Africa. The current and near term biosynthetic production of numerous ingredients or chemicals to replace these crops has relevance for Africa. 
This often involves the use of genetically engineered microbes such as yeast or algae, which feed on sugar. There is potential for negative effects on biodiversity as a result of adoption of SynBio. These can include a reduction in demand for natural plants such as shea, cocoa and cassava and a huge demand for sugar which is used to produce the genetically engineered microbes for production of SynBio products. The sugar is often produced by agribusiness using unsustainable methods and high amounts of water which is becoming difficult to get because of climate change (ETC Group et al., 2018).

Small-molecule natural products produced by endangered organisms that are on the verge of extinction may need alternative methods of production. This is because a continuation of their extraction from natural sources will not be viable. This approach has been used for heterologous production of many complex and high-value phytochemicals in microorganisms (Gandhi, 2019). Yeast can be engineered with ease and it has high growth rates. There is an abundance of infrastructure and industries with expertise in yeast fermentation. Thus, together with bacteria they can be used as hosts for production of medical and non medical bio-products. Also use of plants for production of high value compounds such as flavourings, medicines and oils bring caveats such as long generation rates, dependence on arable land and water and seasonality. Genetic engineering of plants is plagued by long generation times and large polyploidy genomes such as wheat. Using SynBio, multigene pathways can be transplanted to microbes such as yeasts and plant derived waste materials can be used as feedstocks that are converted to useful metabolites. Opiods, cannabinoids, fragrant raspberry ketones and cocoa butter are examples of complex commodities that have been produced in yeast through SynBio techniques (Goold et al., 2018; Carvalho et al., 2017; Lee et al., 2016). This use of microbial hosts in producing plant commodities can thus result in market stability for unstable seasonal plant commodities in Africa.

Implementation of SynBio in agriculture could be hampered by shortage of adequate tools because agriculture is dominated by higher mammals and plants. New techniques for genome design and synthesis, more efficient molecular tools that include CRISPR/Cas9 present more opportunities than new breeds and cultivars development. They can deliver transformative short to long term changes to agriculture. These include engineering of biosensors, novel anti microbials, microbial metabolic engineering, synthetic speciation and mammalian multiplexed CRISPR (Goold et al., 2018). 
This review is aimed at providing an overview of recent progress in the application of SynBio in agriculture as well as on arguments and evidence related to their possible benefits to the African continent while also outlining the risks and governance implications.

\section{Applications of SynBio}

\section{Food issues faced in Africa}

Africa, especially "The Horn of Africa" and Sub-Saharan Africa, is among the most food insecure regions in the world (FAO, 2017). The root cause of food insecurity in Africa is the inability to access food due to poverty (FAO, 2017; IFAD, 2017; UNICEF, 2017; WFP, 2017; WHO, 2017). War and political instability also contribute to food insecurity as they disrupt the normal economic activities such as agriculture and distribution of resources. Trade bans and export restrictions connected to the politics of countries also have negative impacts on food security. Climate change, which has seen the increase in sporadic rains and desertification across the continent is exacerbating poor food security. Additionally, most African countries do not have sustainable agricultural policies to support food security in the coming years. Farmers have little access to modern sustainable agriculture methods and tools resulting in a small percentage of the arable land being used for agriculture. Rapid urbanization and population growth also contribute to food insecurity by disrupting agricultural production and increasing food demands (Fawole et al., 2005).

Malnutrition observed in some African countries is leaving children weak, vulnerable and less able to fight common childhood illnesses such as diarrhoea, acute respiratory infections, malaria and measles. This has more deleterious effects in children living with HIV and AIDS. Adults and adolescents suffer consequences of food insecurity and malnutrition such as decreased energy levels, delayed maturation, growth failure, impaired cognitive ability, diminished capacity to learn, decreased ability to resist infections and illnesses, shortened life expectancy, increased maternal mortality and low birth weight. Individuals experiencing food insecurity are likely to experience and show feelings of alienation, stress and anxiety (FAO, 2017; Fawole et al., 2005).

\section{Possible applications of SynBio to food and agriculture in Africa}

SynBio has a number of applications in the food sector across various sub-sectors. SynBio can be applied for the production of metabolites and health products such as vitamins. 
Artificially produced health products can be packaged as supplements which might be cheaper and more readily available than naturally occurring vitamins and other health products. Another food sector potential application is the production of processing aids in the manufacture of food and food derivatives such as nutraceuticals, probiotics and glycol, nutrients used to raise the value of certain foods or nutrient enriched plants. Nutrient-enriched plants are ideal for people in Africa living in poverty as one plant would be able to address several nutrient needs. It can be used in the production of preservatives such as nisin and artificial flavours and fragrances. Vanilla has been successfully produced from baker's yeast (Hansen et al., 2009) and synthetic saffron has been produced for commercial use at a fraction of the price of natural saffron (Pretorius, 2016). Thus, SynBio can potentially reduce prices of some commodities on the African continent.

SynBio surpasses the application of conventional genetic engineering for crop development and farm management. Drought monitoring and prediction systems (DMAPS) in Africa use various indicators at different temporal and/or spatial resolutions. They are based on remote sensing, land surface modeling, and seasonal climate forecast. These are efficient but drought preparedness remains low (Hao et al., 2017). The development of engineered tomato plants that are able to activate drought protection mechanisms on application of fungal spray can help African farmers prepare for drought (Goold et al., 2018). This helps abate crop loss due to climate change induced droughts and ordinary droughts that have been occurring at least once every ten years in many African countries (Hao et al., 2017).

There is still low adoption of mineral fertilisers use in some African countries due to reasons that include high costs. However, when they are coupled with some good agricultural practices, they can help increase yields (Donkor and Owusu, 2019). Using SynBio, nonleguminous crops that are able to fix atmospheric nitrogen reducing the need for fertilizers were developed (Goold et al., 2018). The technology can be transfered to crops grown on the African continent thereby helping to reduce nutrient associated losses and hence costs of production for many crops. This is because fertiliser is a major cost driver in agriculture and there are periodic shortages that lead to yield losses.

More smart crops with various other advantages such as high yield, drought resistance, and pesticide resistance amongst other adaptations, can be engineered into the synthetic plants 
(Park et al., 2015). The benefit to farm management from SynBio comes through the development of biosensors and the use of agri-intelligence systems that reduce the use of pesticides and fertilizers. The plants will detect when there is a drought or weed threat and activate necessary response mechanisms. This will reduce yield losses and wastage of herbicides which pollute the environment. Food waste processing methods are able to take advantage of this technology and increase the amount of toxic waste removed from the environment (Pretorius, 2016). This will help increase the amount of arable land being cultivated and its productivity as most farmers in Africa cannot afford fertilizers and pesticides.

Given that more than $80 \%$ of the poor Africans keep livestock (FAO, 2009), enhancing animal productivity is a noble way of improving livelihoods. Increased productivity is one way of attaining some of the United Nations Sustainable Development Goals, namely (1) no poverty and (2) zero hunger. One of the major challenges in animal production is that the breeds used by most communal and small-scale farmers have not been genetically improved to enhance productivity. Most of the highly efficient breeds in developed countries have been developed over decades of commercial quantitative genetic selection pressure. Major successes include the ability of broiler chicken to attain more than four kilograms at eight weeks compared to less than a kilogram in 1957 coupled with higher feed conversion efficiency (Zuidhof, 2014). The success that has taken a long time to achieve can be attained in a relatively short time through the application of SynBio. A possible approach is the use of artificial gene synthesis and gene editing techniques to enhance traits of economic importance. Known major genes can be synthesised de novo and subsequently infused in populations using gene drives. Major traits that need improvement include growth, feed conversion efficiency, meat quality and prolificacy. Information from known major genes in exotic breeds such as the double muscling gene/myostatin (Kambadur et al., 1997), growth hormone (Jomane et al., 2015), stearoyl-CoA desaturase and sterol regulatory element binding protein-1 (Mannen, 2011) can be used for artificial gene synthesis and infusion into indigenous cattle. In sheep the booroola gene (Souza et al., 2001; Sahu et al., 2016) is a good candidate for increasing prolificacy. Other possibilities include whole genome editing for traits of economic importance. The success recorded in removing all porcine endogenous retroviruses from the pig gene (Niu et al., 2017) highlights the practicality of the approach. 
Apart from productivity, opportunities for improving animal welfare and food safety were highlighted by Goold et al. (2018).

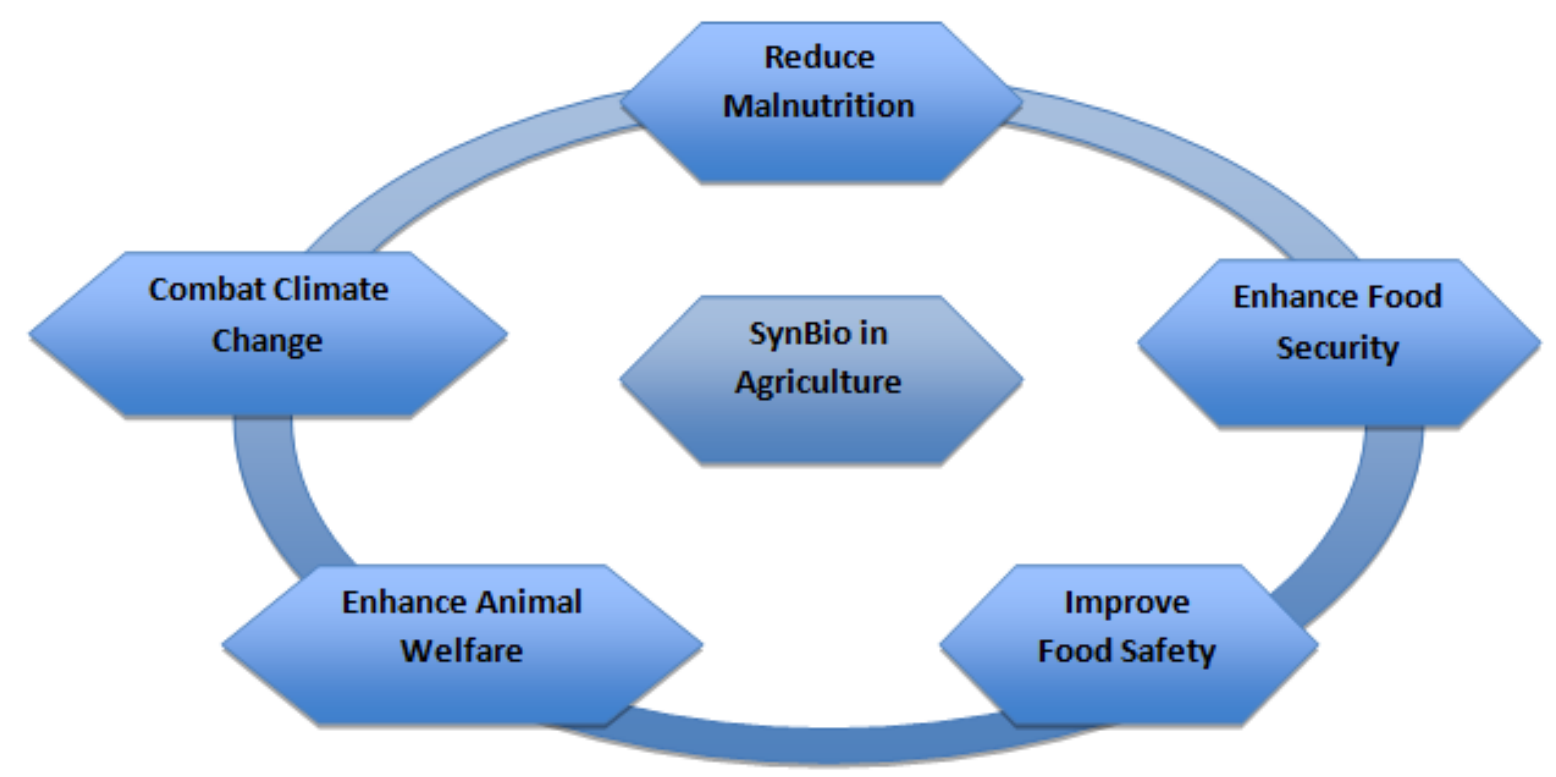

Figure 2: Application of SynBio in Agriculture

\section{Challenges for the adoption of SynBio in Africa}

\section{Risks, advantages and disadvantages of using SynBio}

Risks should be thoroughly assessed before large numbers of synthetic organisms are released out of the laboratory, taking into consideration self-replication, crossing over events and recombination. Thus, there is need for strict monitoring of the technology and its products. Research and development teams should include multiple safeguards in synthetic cells, such as giving them strictly limited life spans or on/off switches, and engineering them to depend on laboratory-specific conditions. They should also keep using unique identifying marks, so that products can be traced back to their "creators".

SynBio offers the advantage of removing the use of selectable markers which are a requirement in many genetic modification applications. It can achieve this using retargetable mobile group II introns commonly called 'targetrons'. These have very high efficiency such 
that there is no requirement for selectable markers (Lambowitz and Zimmerly, 2004). Targetrons function in a wide variety of bacteria. Beyond suicide plasmids which have low efficiency and are unstable, targetrons are first genetic tool of significant utility (Heap et al., 2007).

Non-coding RNA molecules used in RNA interference crops can survive mammalian digestion. They then go on to regulate genes of mammals that consume them. They can also have off target effects. When created using SynBio non-coding RNA molecules will likely have similar effects unless it is addressed in the design stages.

One of the biggest challenges with SynBio is biopiracy of Africa's vast genetic resources. Biopiracy is "the unethical or unlawful appropriation or commercial exploitation of biological materials native to a particular country or territory without providing fair financial compensation to [its] people or government" (Merriam-Webster). Technologies in DNA synthesis and sequencing now mean that genetic information can be transmitted electronically across borders. There may be no need to transport a physical seed or plant. Current laws and policies regulate transfer of physical material only. Thus open access to digital sequences can facilitate further biopiracy. It will thus also cause profit extraction of African plant, animal and microbial resources (ETC Group et al., 2018).

\section{Regulation of SynBio}

\section{The current state of regulation of SynBio}

SynBio is a rapidly evolving, multidisciplinary and promising techno-science field. In particular it is anticipated that it may lead to the $5^{\text {th }}$ industrial revolution (Peccoud, 2016). Strikingly, the technologies have enormous potential to significantly alter genomes of viruses, prokaryotes and eukaryotes. It is thought that when these altered organisms are released into the environment, they can become a biodiversity risk as they may become invasive. Biosecurity risks may also arise if biological weapons are made using SynBio (Trump, 2017). All these concerns raise environmental, health, social, legal and ethical issues (The Parliamentary Office of Science and Technology, 2015). In light of these concerns, some countries have regulations that govern the use of SynBio. Often where regulatory provisions are non-existent in countries, regulatory authorities have often resorted to the use of the precautionary approach principle (UN, 2011). 


\section{Regulation of SynBio in Europe}

The regulations governing their use in Europe exist at various levels of implementation. In the majority of the cases, the regulations originally produced for the regulation of GMOs and their derivatives are revised to suit the current technological innovations. In this regard, for the last two decades, two EU GMO directives namely the Contained Use Directive (2009/41/EC) and the Deliberate Release Directive (2001/18/EC) have been used for the regulation of SynBio products. There are regulations for laboratory research work and the release of GMOs into the environment. However, in the current EU GMO regulatory framework, the genetically modified (GM) organism is compared with an equivalent nonGMO. However, as the number of traits and sources of genetic materials increase, finding a comparator organism becomes a daunting task. Since these complex organisms are developed in a step by step manner and regulatory approvals are sought at each stage, the EU Scientific Committees have suggested that a complex organism developed earlier in the chain could be used as a comparator if it has a history of safe use (Parliamentary Office of Science and Technology, 2015).

\section{Regulation of SynBio in the United States of America}

The United States of America (USA) is using the same regulatory frameworks for GMOs for the regulation of SynBio. The present state and form of the legal regulatory framework for GMOs is applied to SynBio and products derived thereof. Agencies involved in the implementation of the regulatory system are the U.S. Department of Agriculture's Animal and Plant Health Inspection Service (APHIS), the U.S. Environmental Protection Agency (EPA), and the U.S. Food and Drug Administration (FDA) (Carter, et al., 2014). Elsewhere, these agencies are viewed as organizations who have limited regulatory authority to regulate some SynBio products. For instance, APHIS regulates organisms in which plant pests or components thereof have been used to modify the plant. It is most likely that development methods of SynBio derived organisms will not be covered by these regulations (Carter et al, 2014). Thus, the products will go without regulatory oversight because they are not explicitly covered by the existing statutes. The responsible and enforcing agency is thus rendered 'powerless'. In the case of EPA, as modified microbes become more complex, risk assessments will become more difficult, requiring more financial resources and expertise. 


\section{Regulation of SynBio in Africa}

Despite the potential positive impact of SynBio, it is important to note that the regulatory framework for SynBio products including synthetic organisms still has to be developed by some African countries. There is no distinctive line between what is traditionally labelled 'natural' and what should be labelled 'synthetic'. Even African countries with wellestablished systems for regulation of genetically modified organisms (GMOs) such as Kenya, and South Africa, are yet to put in place regulations which are specifically meant for SynBio. It is worth noting that certain provisions contained in their current GMO regulations may be extended to SynBio since it builds on modern biotechnology methodologies and techniques. As more complex organisms are produced by SynBio there will be a need to develop regulations for more comprehensive risk analysis (The Parliamentary Office of Science and Technology, 2015). This is because the comparative principle used for the regulation of GMOs may not be applicable if organisms which are fundamentally different from natural organisms are produced using SynBio.

Nigeria amended the National Biosafety Management Agency Act of 2015 in 2019 to cater for the regulation of SynBio. A new section was inserted (NBMA, 2019) and it reads as follows:

25A. Application of gene drive, gene editing and synthetic biology

"No person, institution or body shall carryout gene drive, gene editing and synthetic biology except with the approval of the Agency". Supporting regulations however are still to be developed.

In Zimbabwe SynBio is regulated through the National Biotechnology Authority Act [Chap.14.31] of 2006. Subsection 3 (2) c of the Act states that the Act shall apply to - (c) any activity involving biological and molecular engineering technologies such as metabolic engineering, proteomics, metabolomics, nanotechnology, genetic modification, cloning, DNA-chip technology and bioinformatics; and such other technologies as may be declared by the authority to constitute potentially harmful research or undertaking. SynBio products are currently classified as genetically engineered (GE) and are covered under the current regulations hence the NBA Act of 2006 is used. However, although a comprehensive National Biosafety Framework exists for effective regulation of biotechnology, future reviews of regulations to accommodate complex SynBio processes cannot be ruled out. Furthermore, future reviews of the regulations will be motivated by the fact that globally the 
definition of SynBio and products is ambiguous and SynBio produces more complex products which potentially present legal issues. The NBA Act does not make specific reference to SynBio and to avoid any ambiguity, a statutory instrument which supports the NBA Act requires gazetting.

The African continent needs to assume a harmonized position on regulation and governance of SynBio, whether it should be case specific or not, process based or product based. These gaps in the regulatory frameworks need to be addressed if Africa is to derive maximum benefit from SynBio whilst minimizing the risks associated with the technology. This is critical given that fellow African countries such as South Africa are among the leading researchers of SynBio (Oldham et al., 2012).

\section{International treaties}

Misuse of SynBio presents threats to international peace and security hence this section looks at some of the international treaties governing the use of SynBio. The Biological Weapons Convention (BWC) bans the development, production and stockpiling of all weapons of mass destruction (United Nations Office for Disarmament Affairs, 2018). This includes microbial, other biological agents and toxins for which there is no justified use for preventative, protective or other peaceful cause. The BWC provides for any unforeseen misuse of SynBio techniques (Parliamentary Office of Science and Technology, 2015).The United Nations Security Council Resolution 1540 of April 2004 requires all UN member states to refrain from supporting terrorists to make, obtain, transport, develop, possess, use or transfer any nuclear, chemical or biological weapons (UN Office for Disarmament Affairs, 2018). This resolution and the BWC provide a safeguard measure for guiding against the misuse of SynBio.

Whereas, the Convention on Biological Diversity (CBD) at its $13^{\text {th }}$ meeting held in Mexico in 2016 invited parties to take a precautionary approach on SynBio. It noted that current living organisms developed using SynBio and those in early stages of research and development fall within the Cartagena Protocol on Biosafety (CPB) definition for living modified organisms (LMOs). As such, the current risks assessment methodologies under the CPB can be applied for these, however they may need to be reviewed as the technology advances. CBD parties 
also noted that it is not clear whether the final products of the early stages of SynBio research and development would fall under the CPB LMO definition.

There are a number of capacity limitations and challenges that need to be addressed globally if the countries are to effectively regulate SynBio products. Addressing these issues would go a long way in ensuring that countries benefit from these technologies whilst protecting human and animal health and the environment. SynBio is rapidly advancing and current regulations may not adequately cover future products of the technologies. Taking cognisance of both benefits and risks of the technology (Good et al., 2018), countries need to come up with allencompassing regulatory frameworks which will not stifle development, at the same time making sure that adequate biosafety and biosecurity measures are put in place to prevent misuse of the technologies. In the case of Africa, it is worth noting that the judicious application of synthetic biology can alleviate food and energy security, reduce poverty, boost industrial growth, reduce greenhouse gases and promote environmental conservation (Garang and Onkware, 2016).

\section{Future perspectives and conclusion}

Adoption of SynBio has the potential to improve food security and livelihoods in Africa. Considering that most African countries are yet to accept genetically modified organisms, the adoption of SynBio might seem arduous. However, there are countries like Zimbabwe where, growing of GE's is not permitted but controlled research on and food processed from GE's is permissible. It is important that stakeholders' perspectives on GE's are investigated: the understanding of GE's definition(s), methods employed in obtaining GE's, knowledge of SynBio, source of information and willingness to fund research of GE's. This will improve platforms for knowledge transfer, identifying key challenges and mapping solutions. It is knowledge that will assist in developing informed polices that have meaningful impact of the socioeconomic factors.

Without a clear policy on GE's, public funds will not be readily channeled towards research on GE's. In the countries that are leading in research and adoption of SynBio and other GE's, their governments have made significant investments of more than US $\$ 30$ billion dollars however, most African countries are lagging behind (World Bank, 2015). 5rrrr5rOther funds have come from private players and industry. The government, industry and academia are 
working together in improving knowledge, adoption and safety of SynBio and other GE's. Industry will only fund research where there is a guaranteed return on investment. With the current policy in Zimbabwe and other African nations where GE's are limited, industry is less likely to invest in research on GE's. It becomes a chain: No good policy -> no funding -> no research -> no information -> no good policy. This cycle needs to be broken. Though SynBio presents a golden opportunity for improving livelihoods in Africa, its success can only be realized if the policy and legislative environment is conducive. The diagram illustrates the critical activities that the majority of African countries need to consider in making SynBio a success in transforming livelihoods.

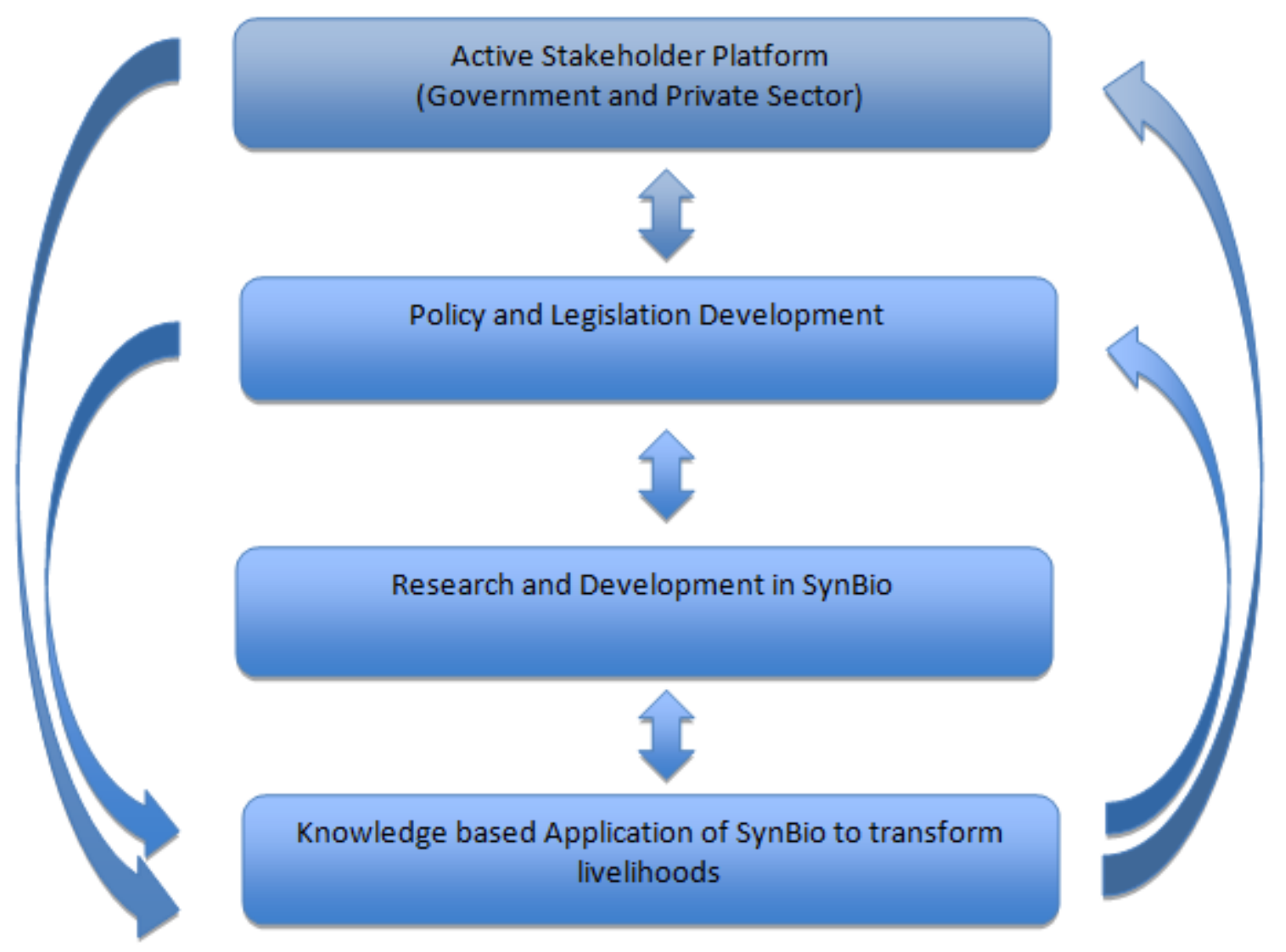

Figure 3: Flow chart of critical activities to be adopted by the majority of African countries to make the adoption of SynBio successful 
SynBio thus offers great opportunities although it can result in many adverse effects on the environment and economies in Africa. Its adoption is however still low. It seems to be following the trajectory of GMOs which to date are being legally cultivated in Sudan and South Africa only out of about 50 African countries. These limited experiences therefore provide limited data on the effects of some of these GM technologies on the continent.

\section{References}

1. Adwell , M., 2011. Synthetic Biology Research: What Are The Benefits And Risks?. The 9 Billion, 09 April.

2. Alleyne, G., Breman, J. H., Buss, P., Hotez, P. J., Morel, C. and Remme, J.H. (2004). Combating Tropical infectious diseases: Report of the Disease Control Priorities in Developing Countries Project. Clinical Infectious Diseases 38: 871 - 878. DOI: $10.1086 / 382077$

3. Allied market research, 2019. Global Synthetic Biology Market (Products, Technologies, Applications and Geography) - Global Opportunity Analysis and Forecast - 2013 - 2020. http://www.alliedmarketresearch.com/synthetic-biologymarket.

4. Amos M., Goñi-Moreno A. (2018). Cellular computing and synthetic biology, in Computational Matter, eds Stepney S., Rasmussen S., Amos M., editors. (Berlin: Springer; ) 93-110.

5. Bedau, M. and Pennisi, E. (2010). Synthetic Biology breakthrough: Your Questions Answered, Science Magazine, May 2010. www.news.sciencemag.org/sciencenow/2010/05/syntheticbiology-news

6. Belkin, Shimshon; Yagur-Kroll, Sharon; Kabessa, Yossef; Korouma, Victor; Septon, Tali; Anati, Yonatan; Zohar-Perez, Cheinat; Rabinovitz, Zahi; Nussinovitch, Amos (April 2017). "Remote detection of buried landmines using a bacterial sensor". Nature Biotechnology. 35 (4): 308-310. doi:10.1038/nbt.3791. ISSN 1087-0156.

7. Bergin, J. 2014. Synthetic Biology: Global Markets, BCC Research

8. Bos, S., Gadea, G. and Despres, P. 2018. Dengue: a growing threat requiring a vaccine development for disease prevention. Pathogens and Global Health. DOI: $10.1080 / 20477724.2018 .1514136$

9. Carter, S.R., Rodemeyer, M., Garfinkel, M. S. Snd Friedman, R. M. 2014. Synthetic Biology and the U.S. Biotechnology Regulatory System: Challenges and Options. 
Available at: http://www.jcvi.org/cms/research/projects/synthetic-biology-and-the-usbiotechnology-regulatory-system/overview/.

10. Carvalho Â., Hansen E.H., Kayser O., Carlsen S., Stehle F. 2017. Designing microorganisms for heterologous biosynthesis of cannabinoids. FEMS Yeast Res. 17:1-11. doi: 10.1093/femsyr/fox037.

11. Chan, E. D. And Iseman, M. D. (2002). Current Medical treatment for tuberculosis. BMJ 325: 1282- 1286. DOI: 10.1136/bmj.325.7375.1282.

12. Chen, L., Blanchard, A. E. and Ting, L. 2017. An integrative circuit-host modelling framework for predicting synthetic gene network behaviours. Nature Microbiology DOI: $10.1038 / \mathrm{s} 41564-017-0022-5$

13. Coleman, J. R., Futcher, B., Mueller, S., Nimnual, A., Papamichail, D., Skienna, S., Ward, C. B. And Wimmer, E. (2010). Live attenuated influenza virus vaccines by computer aided rational design. National Biotechnology 28: 723 - 726. DOI: $10.1038 /$ nbt. 1636

14. Coleman, J. R., Futcher, S., Mueller, S., Papamichail, D., Skienna, S. And Wimmer, B. (2008). Virus attenuation by genome scale changes in codon pair bias. Science $\mathbf{3 2 0}$ : 1784- 1787. DOI: 10.1126/science.1155761

15. Conceição, P., Levine, S., Lipton, M. and Warren-Rodríguez, A. 2016. Toward a food secure future: Ensuring food security for sustainable human development in Sub$\begin{array}{llll}\text { Saharan } & \text { Africa. } & \text { 6ood } & \text { Policy }\end{array}$ www.sciencedirect.com/article/pii/S030691921600021X

16. Dana, G. V., Kuiken, T., Rejeski, D. and Snow, A. A. 2012. Four steps to avoid a synthetic-biology disaster. Nature 29:483:29. DOI: 10.1038/483029a

17. Ediriweera, D. And Karunapema, P. 2016. Unconditional Probability of dying due to Non Communicable Diseases on the rise: Cause and death analysis from 2002 to 2010. Conference Paper: $129^{\text {th }}$ Anniversary International Medical Congress of the Sri Lanka Medical Association, Colombo, Sri Lanka.

18. Edwards, B. 2014. Taking Stock of Security Concerns Related to Synthetic Biology in an Age of Responsible Innovation. Front Public Health 2: 79. DOI: 10.3389/fpubh.2014.00079

19. ETC Group, Third World Network and African Centre for Biodiversity. 2018. What Does Synthetic Biology Mean for Africa?

20. FAO, 2009. The State of Food and Agriculture. Livestock in the Balance. Rome. 
21. FAO, 2017. Hunger and Food security. State of Food Insecurity (SOFI 2017).

22. FAO, IFAD, UNICEF, WFP AND WHO, 2017. The state of food security and nutrition in the world 2017, Rome: FAO. www.data.unicef.org/wpcontent/uploads/2017/12/web_I7787EN_SOFI2017_InBrief.pdf

23. Fawole, W. O., Ozkan, B. and Ilbasmis, E. 2005. Food Insecurity in Africa in Terms of Causes, Effects and Solutions: A case study of Nigeria. Konya, ResearchGate. DOI: 10.24925/turjaf.v5i6.629-636.1113.

24. Funk, C., Dettinger, M. D., Michaelsen, J. C., Verdin, J. P., Brown, M. E., Barlow, M. and Hoell, A. 2008. Warming of the Indian Ocean threatens Eastern and Southern African food security but could be mitigated by agricultural development. PNAS 105:11081-11086. DOI: 10.1073/pnas.0708196105

25. Gandhi, G., S., 2019. Current Developments in Biotechnology and Bioengineering. Chapter 8 -Synthetic Biology for Production of Commercially Important Natural Product Small Molecules. Synthetic Biology, Cell Engineering and Bioprocessing Technologies. Pages 189-205.

26. Garang, B. and Onkware, A. (2016). Redirecting the Wheels of Natural Progression: Review of Synthetic Biology and the African Biotechnology Revolution. Bioengineering and Bioscience, [online] 4(2), pp.11-19. Available at: https://pdfs.semanticscholar.org/81bc/f384afb50e07ed842693de2a9ceeb1d1f26b.pdf? ga=2.255418056.1331119020.1573054035-240779808.1573054035 [Accessed 6 Nov. 2019].

27. Gibson, D. G., Glass, J. I., Lartigue, C., Noskov, V. N., Chuang, R. Y., Algire, M. A., Benders, G. A., Montague, M. G., Ma, L., Moodie, M. M., Merryman, C., Vashee, S., Krishnakumar, R., Assad-Garcia, N., Andrews-Pfannkoch, C., Denisova, E. A., Young, L., Qi, Z. Q., Segall-Shapiro, T. H., Calvey, C. H. 2010. Creation of a bacterial cell controlled by a chemically synthesized genome. Science 329: 52-56. DOI: $10.1126 /$ science.1190719.

28. Goñi-Moreno, A., and Nikel, P. I. (2019). High-Performance Biocomputing in Synthetic Biology-Integrated Transcriptional and Metabolic Circuits. Frontiers in bioengineering and biotechnology, 7, 40. doi:10.3389/fbioe.2019.00040

29. Goold, H. D., Wright, P. and Hailstones, H. 2018. Emerging Opportunities for Synthetic Biology in Agriculture. Genes 9:341. DOI: 10.3390/genes.9070341. 
30. Gordon, Y. J., McDermot, A. M. And Romanowski, E. G. (2005). A review of antimicrobial peptides and their therapeutic potential as anti infective drugs. Current Eye Research 30:505 - 511. DOI: 10.1080/02713680590968637

31. Green, A. E., Amezquita, A., Le Marc, Y., Bull, M. J., Connor, R. T. and Mahenthiralingam, E. 2018. The consistent differential expression of genetic pathways following exposure of an industrial Pseudomonas aeruginosa strain to preservatives and laundry detergent formulation. Microbiology letters 365. DOI: 10.1093/femsle/fny062.

32. Guardiola, E., Fragos, J., Abril, M. R. And Spain, B. 2018. Medical Information in the Pharmaceutical Industry: Recommendations of the First Guide to Good Practices of Good Health. Conference Paper. www.researchgate.net/publication/325056377

33. Guiziou, S., Bonnet, J., Moreau, V., Ulliana, F. And Lechere, M. 2018. An automated Design Framework for Multicellular Recombinanse Logic. ACS Synthetic Biology 7: 1406-1412., DOI; 10.1012/acssynbio.8b00016.

34. Hansen, E. H., Moller, B. L., Kock, G. R., Bunner, C. M., Kristensen, C., Jensen, O. R., Okkels, F. T., Olsen, C. E., Motawaia, M. S. and Hansen, J. 2009. De Vovo Biosynthesis of Vanillin in Fission Yeast (Schizosaccharomyces pombe) and Baker's yeast(Saccharomyces cerevisiae). Applied and Environmental Microbiology, 75: 2765-2774. DOI: 10.1128/AEM.02681-08

35. Hao, Z., Yuan, X., Xia, Y., Hao, F. and Singh, P. V. 2017. An overview of drought monitoring and prediction systems at regional and global scales. American Meteorological Society. 1879-1896. DOI:10.1175/BAMS-D-15-00149.1

36. Heap, J. T., Pennington, O. J, Cartman, S. T., Carter, G. P. and Minton, N. P. 2007. The ClosTron: A universal gene knock-out system for the genus Clostridium. Journal of Microbiological Methods 70: 452-464. DOI: 10.1016/j.mimet.2007.05.021. https://www.acbio.org.za/sites/default/files/documents/What\%20does\%20Synthetic\% 20Biology\%20mean\%20for\%20Africa.pdf

37. https://www.bccresearch.com/market-research/biotechnology/synthetic-biologybio066c.html

a. https://www.who.int/news-room/facts-in-pictures/detail/malaria

38. Isaacs, F. J., Carr, P. A., Wang, H. H., Lajoie, M. J., Sterling, B., Kraal, L., Tolonen, A. C., Gianoulis, T. A., Goodman, D. B., Reppas, N. B., Emig, C. J., Bang, D., Hwang, S. J., Jewett, M. C., Jacobson, J. M. and Church, G. M. 2011. Precise 
manipulation of chromosomes in vivo enables genome-wide codon replacement. Science 333: 348-353. DOI: 10.1126/science.1205822.

39. Jain, A., Bhatia, P. and Chugh, A. 2012. Microbial Synthetic Biology for Human Therapeutics. Systems and Synthetic Biology 6: 8-22. DOI: 10.1007/511693-0129092-0

40. James, S. H. 2017. Measles, Mumps and Rubella viruses. Infectious Diseases $4^{\text {th }}$ Edn.

41. Jing Liang, Y. L. 2011. Synthetic Biology: Putting Synthesis into Biology. Wiley Interdisciplinary Review of Systems Biology and Medicine 3:7-20. DOI: 10.1002/wsbm.104.

42. Jomane, F. N., Ishida, T., Morimoto, K., Fujishita, N., Tokunaga, T., Hararada, H., and Morita T. 2015. Genetic Polymorphisms and Their Association with Growth and Carcass Traits in Japanese Black Steers under Progeny Testing. Journal of Warm Regional Society of Animal Science 58: 217-224.

43. Juma, A. P., Mohamed, F. S., Mwagomba, M. L. B., Ndinda, C., Mapa-tassou, C., Oluwasanu, M., Oladepo, O., Abiona, O., Nkhata, J. M., Wisdom, P. J. and Mbanya, J. C. 2018. Non-communicable disease prevention policy process in five African countries author. BMC Public Health. 18 (Suppl 1):961

44. Kambadur, R., Sharma, M., Smith, T. P. L. and Bass, J .J. 1997. Mutations in myostatin (GDF8) in Double-Muscled Belgian Blue and Piedmontese Cattle. Genome Research 7: 910-915.

45. Khalil, A. and Collins, J. 2010. Synthetic biology: applications come of age. Nature Reviews Genetics 11: 367-379.

46. Kindsmuller, K. And Wagner, R. (2011). Synthetic Biology: Impact of the design of innovative vaccines. Human Vaccines 7: 662. DOI: $10.4161 / \mathrm{hv}, 7.6 .14987$

47. König, H., Frank, D., Heil, R. and Coenen, C. 2013. Synthetic Genomics and Synthetic Biology Applications Between Hopes and Concerns. Current Genomics. 14, 11-24.

48. Lee D., Lloyd N.D.R., Pretorius I.S., Borneman A.R. Heterologous production of raspberry ketone in the wine yeast Saccharomyces cerevisiae via pathway engineering and synthetic enzyme fusion. Microb. Cell Fact. 2016;15:49. doi: 10.1186/s12934016-0446-2.

49. Li, L., Saade, F. And Petrovsky, N. 2017. The future of Human DNA vaccines. Journal of Biotechnology 162: 2-3.DOI: 10.1016/j.jbiotech.2017.08.012

50. Liu, W. and Stewart, C. N. Jr. 2015. Plant synthetic biology. Trends in Plant Science 20:309-17. 
51. Lu, T. K., Khalil, A. S. and Collins, J. J. 2009. Next-generation synthetic gene networks. National Biotechnology 27: 1139-1150.

52. Mandel, G. N., Marchant, G. E. 2014. The Living Regulatory Challenges of Synthetic Biology. Iowa Law Review 100:155 - 200.

53. Mannen, H. 2011. Identification and utilization of genes associated with beef qualities. Animal Science 82: 1-7.

54. McDaniel, R. and Weiss, R. 2005. Advances in synthetic biology: on the path from prototypes to applications. Current Opininions in Biotechnology 16:476-83.

55. Millar-Haskell, C.P., Dang, A.M and Gleghorn, J.P. (2019) "Coupling synthetic biology and programmable materials to construct complex tissue ecosystems". MSR Communications. Cambridge Press, 9(2), pp. 421-432. doi: 10.15557/mrc.2019.69.

56. Mitchell, J. 2018. Life 2.0: Inside the Synthetic Biology revolution. COSMOS 78: The Science of Everything

57. National Biosafety Management Agency (NBMA). (2019). [online] Available at: https://nbma.gov.ng/wp-content/uploads/2017/06/Amendment-of-NBMA-Act2019.pdf [Accessed 6 Nov. 2019].

58. National Biotechnology Authority Act [Chap.14:31] of 2006

59. Niu, D., Wei, H. J., Lin, L., George, H., Wang, T. B., Lee, I. H., Zhao, H. Y., Wang, Y., Kan, Y., Shrock, E. 2017. Inactivation of porcine endogenous retrovirus in pigs using CRISPR-Cas9. Science 357: 1303-1307.

60. OECD, Royal Society (2010). Symposium on opportunities and challenges in the Emerging Field of Synthetic Biology - Synthesis Report. DOI: 10.1787/9789264086265-en

61. Oldham, P., Hall, S. and Burton, G. 2012. Synthetic Biology: Mapping the Scientific Landscape. PLoS ONE 7: e34368. DOI:10.1371/journal.pone.0034368

62. Paddock, C. (2010). Synthetic Biology Breakthrough: Bacteria with manmade Genome Self Replicates in Medical News Today. www.medicalnewstoday.com/articles/189458, php

63. Park, S. Y., Peterson, F. C., Mosquna, A., Yao, J., Volkman, B. F. and Cutler, S. R. 2015. Agrochemical control of plant water use using engineered abscisic acid receptors. Nature 520: 545- 548

64. Pasad, V., Fojo, T. and Brada, M. (2016). Precision oncology: origins, optimism and potential. Lancet Oncology 17: 81. DOI: 10.1016/5170-2045(15)00620-8 
65. Path. 2013. Sanofi and PATH announce the launch of large-scale production of semisynthetic artemisinin against malaria. [ONLINE] Available at: https://path.org/media-center/sanofi-and-path-announce-the-launch-of-large-scaleproduction-of-semisynthetic-artemisinin-against-malaria/. Accessed 23 October 2018.

66. Peccoud, J. 2016. Synthetic Biology: fostering the cyber-biological revolution. Synthetic Biology 1:1-7.

67. Pozzi, C., Tassone, G. and Mangani, S. 2018. X ray crystallography contributions to drug discovery against parasites. Annual Reports in Medicinal Chemistry 51: 175230. DOI:10.1016/bs.armc.2018.08.005

68. Pretorius, S. 2016. Application of Synthetic Biology to increased Agricultural Productivity in Australia. Agricultural Innovation 69: 2.

69. Ribeiro. B. And Shapira, P. 2018. Anticipating governance challenges in synthetic biology: Insights from biosynthetic menthol. Elsevier 139: 311-320

70. Sahu, A. mR., Jeichitra, V., Ramanujan, R. and Angamuthu, R. 2016. Genetic Polymorphisms of Myostatin (MSTN) Gene in sheep breeds. Journal of Animal Research 6: 18. DOI: 10.5958/2277-940X.2016.00013.9

71. Schmidt, C. 2010. Environmental Health Implications of a New Field. Environmental Health Perspect. Synthetic Biology 118: 118-123.

72. Secretariat of the Convention on Biological Diversity, 2015. Synthetic biology, Montreal,Technical Series No. 82.

73. Serrano, L., 2007. Synthetic biology: promises and challenges. NCBI, 18 December, Volume 3, pp. 157-158.

74. Souza, C. J, MacDougall, C., Campbell, B. K, McNeilly, A. S. and Baird, D. T. 2001. The Booroola $(\mathrm{FecB})$ phenotype is associated with a mutation in the bone morphogenetic receptor type 1B (BMPR1B) gene. The Journal of Endocrinology 169: R1-6.

75. Taylor, D. 2016. The Pharmaceutical Industry and the future of drug Development. Issues in Environmental Science and Technology 41: Pharmaceuticals in the Environment. DOI: 10.1039/9781782622345-00001

76. Teo, S. C., 2014. Whole Cell-based Biosensors for Environmental Heavy Metals Detection. Annual Research and Review in Biology , 11 January, 4(17), pp. 26632674. 
77. The Parliamentary Office of Science and Technology, 2015. Regulation of Synthetic Biology, London: PostNote.

78. Trump, B.D. 2017. Synthetic biology regulation and governance: Lessons from TAPIC for the United States, European Union, and Singapore. Health Policy 121: 1139-1146.

79. UN Office for Disarmament Affairs (UNODA), UN Security Council Resolution 1540 (2004). United Nations. Available at: https://www.un.org/disarmament/wmd/sc1540/ Accessed February 25, 2018.

80. UNEP, 2011. Food Security in the Horn of Africa: The Implications of a Drier, Hotter and More Crowded Future, s.1.: unep.org/GEAS/.

81. United Nations Office for Disarmament Affairs, Biological Weapons. United Nations. Available at: https://www.un.org/disarmament/wmd/bio/ [Accessed February 25, 2018].

82. World Bank. 2015. Research and development expenditure (\% GPD). www.data.worldbank.org

83. World Health Organisation Report, 2011. Global status report on Non Communicable diseases, 2010. www.who.int/nmh/publications/ncd_report_full_en_pdfBaxter, D. (2007). Active and passive immunity, vaccine types, excipients and licensing. Occupational Medicine 57:552 - 556. DOI: 10.1093/occmed/kqm110

84. World Health Organisation, 2019. News room, facts in pictures.

a. www.fao.org/3/a-I7695e.pdf

b. www.fao.org/docrep/012/i0680e/i0680e00.htm

85. Xiang, Y., Dalchau, N., \& Wang, B. (2018). Scaling up genetic circuit design for cellular computing: advances and prospects. Natural computing, 17(4), 833-853. doi:10.1007/s11047-018-9715-9

86. Zuidhof, M. J., Schneider, B. L., Carney, V. L., Korver, D. R. and Robinson, F. E. 2014. Growth, efficiency, and yield of commercial broilers from 1957, 1978, and 2005. Poultry Science 93 1-13. 